\title{
Association between auditory temporal and visual processing in reading skill
}

\author{
Ana Carla Oliveira Garcia ${ }^{1,2,3}$ \\ https://orcid.org/0000-0003-4664-0073 \\ Douglas de Araújo Vilhena 3 3,4,5 \\ https://orcid.org/0000-0003-2670-7963 \\ Márcia Reis Guimarães ${ }^{3}$ \\ https://orcid.org/0000-0002-5475-5375 \\ Ângela Maria Vieira Pinheiro 3,5 \\ https://orcid.org/0000-0002-5852-4320 \\ Teresa Maria Momensohn-Santos ${ }^{1}$ \\ https://orcid.org/0000-0003-4751-0721
}

\begin{abstract}
Pontifícia Universidade Católica de São Paulo (PUC-SP), Programa de Pós-Graduação em Fonoaudiologia, São Paulo, São Paulo, Brasil.

University of Montreal, Institut Universitaire de Gériatrie de Montréal, École d'orthophonie et d'audiologie, Montreal, QC, Canada.

${ }^{3}$ Hospital de Olhos de Minas Gerais Dr. Ricardo Guimarães, Laboratório de Pesquisa Aplicada à Neurociências da Visão (LAPAN), Belo Horizonte, Minas Gerais, Brasil.

Universidade do Porto, Faculdade de Psicologia e Ciências da Educação, Porto, Porto, Portugal.

${ }^{5}$ Universidade Federal de Minas Gerais, Programa de Pós-Graduação em Psicologia: Cognição e Comportamento, Laboratório de Processos Cognitivos (LabCog), Belo Horizonte, Minas Gerais, Brasil.
\end{abstract}

Source of support: This study was financed in part by the Coordenação de Aperfeiçoamento de Pessoal de Nível Superior -Brasil (CAPES) - Finance Code 001.

Conflict of interests: Nonexistent

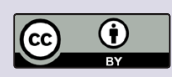

Received on: May 23, 2019 Accepted on: September 12, 2019

Corresponding address:

Ana Carla Oliveira Garcia

Rua Itapira 219, Jardim Mesquita CEP 12327-689 - Jacaré, São Paulo, Brasil

E-mail: anacarlagarciausa@gmail.com

\section{ABSTRACT}

Purpose: to verify whether students screened with altered auditory temporal processing are more likely to present altered visual processing.

Methods: the sample consisted of 68 children, aged from 9 to 12 years, $53 \%$ males, from the $5^{\text {th }}$ and $6^{\text {th }}$ grades of a public school. All children with alterations in the audiological or ophthalmological evaluation were excluded. The Duration Pattern Test (screening for auditory temporal skill), the Reading Perceptual Scale (visual stress symptom questionnaire and colored overlays selection) and the Rate of Reading Test (number of words correctly read per minute) were used. Appropriate statistical tests were applied adopting the significance level lower than 0.05 .

Results: participants screened with abnormal auditory processing had higher visual stress symptoms and lower reading rate, with a significant and moderate effect $(p<0.05 ; d<0.71)$, when compared to their peers with normal auditory processing. Among the children with altered Duration Pattern Test, 58\% improved the reading rate with the use of colored overlays, whereas $29 \%$ did so in the control group (Odds Ratio $=3.4, p=0.017$ ).

Conclusion: children screened with altered auditory temporal processing presented a three times higher possibility of association with visual processing alterations, due to shared magnocellular system

Keywords: Reading; Learning; Vision; Hearing; Auditory Perception 


\section{INTRODUCTION}

For the last 20 years, progress in neurosciences and cognitive psychology have contributed to a better understanding of neuronal mechanisms involved in the act of reading. Reading is a complex multisensorial process, which involves visual perception/processing, visual memory, visual-auditory association, auditory memory/recognition, phonological processing, oral expression, and verbal processes ${ }^{1-3}$.

An essential aspect for the proficiency in reading is the temporal sequence processing of auditory and visual information, which enables the forming of precise representations of the order of sounds in a word and the visual sequencing of letters ${ }^{4.8}$. The auditory temporal processing may be defined as the perception of change in sound within a specific time period; i.e., it refers to the ability of noticing or distinguishing auditory stimuli presented in quick succession?. As for the temporal processing of visual information in reading, it depends on the perception of movement and contrast, the preservation of spatial order for the quick recognition of the unchanging strokes of the letters that form the words, and the comparison to the images previously stored in our memory (visual vocabulary). Just as the dynamic auditory processing is related to the perception of speech and to phonological awareness, the dynamic visual processing is related to orthographic skills, and both processes are predictive of reading and writing skills development ${ }^{4}$.

Both the auditory and the visual sequencing depend on the properties of the transient system in the brain, which is mediated by neurons of the magnocellular system, with quick temporal processing and low spatial processing ${ }^{10,11}$. The well-succeeded sequencing depends on the timing accuracy of auditory and visual sensory inputs, whose neural pathways are integrated into the thalamus by the medial and lateral geniculate nucleus, respectively. The dorsal magnocellular system mediates the temporal sequencing as it registers the amplitude and the order of the changes in attention of eye movements while inspecting each word ${ }^{11}$. It plays a vital role in controlling the driving of visual attention to reading, which contributes to the quick and precise recognition of each sequential letter within a word ${ }^{8}$. This system is also important for detecting changes in lighting and movements, and controlling visual search, among others.

Part of the dyslexics has a deficit in the magnocellular system, characterized by decreased sensibility to contrast in low spatial frequency with high temporal frequency ${ }^{4,12-14}$. The magnocellular system establishes the time each eye fixation lasts, in addition to the direction taken by the saccadic eye movements in between pauses. A difficulty in the visual magnocellular system leads to a decreased stability of eye fixation on the letter or word, consequently causing progressive discomfort and visual stress. The foveal analysis of static visual acuity, mediated by the neurons of the parvocellular system (which has low temporal processing and high spatial processing), doesn't have enough information about reading fluency or the quality of dynamic visual processing.

Visual processing disorders cause a series of symptoms and signs ${ }^{15,16}$, either isolated or in comorbidity with development disorders, as in dyslexia ${ }^{17,18}$, attention deficit hyperactivity disorder ${ }^{19}$, Tourette syndrome, and autism spectrum disorder ${ }^{20}$. The treatment with colored overlays and filters improves reading performance and reduces the prescription of medications inpatients whose restlessness and lack of attention result from avoidance behavior due to symptoms of visual stress adaptation to varied lighting conditions s $^{15,21-25}$.

In order to investigate the association between visual and auditory processing, this study aims to verify whether students screened with alterations in auditory temporal processing are more likely to present visual processing disorders, when compared to their peers with normal auditory processing.

\section{METHODS}

\section{Participants}

Only the children who signed the Informed Assent Form and whose parents or adults responsible for them signed the Informed Consent Form participated in the research, as warranted by the National Health Council Resolution 466/12. Data collection took place after the approval by the Research Ethics Committee of the Pontifical Catholic University of São Paulo - PUC-SP,in accordance with the Certificateof Presentation for Ethical Consideration (CAAE, as abbreviated in Portuguese) number 52510115.9.0000.5482.

This is an observational cross-sectional study. The sample was composed of 68 children, aged from 9 to 12 years -11.2 years in average ( \pm 0.7 years), $53 \%$ male, properly enrolled in the $5^{\text {th }}(n=24)$ and $6^{\text {th }}(n$ $=44$ ) grades of Elementary and Middle School at a public institution in the city of Jacareí, state of São Paulo. In the School Performance Evaluation System 
of the State of São Paulo (SARESP, its Portuguese acronym), the school at issue obtained a proficiency level superior to the goal established by the São Paulo State Department of Education. As inclusion criteria, all the children without central visual or auditory alterations participated in the research. Fourteen children (not counted in the sample) were excluded due to presenting altered ophthalmic evaluation (e.g., having myopia, astigmatism, hyperopia, low vision, or wearing glasses), or audiological evaluation (e.g., threshold higher than $25 \mathrm{~dB} \mathrm{HL}$ in a $250-\mathrm{to}-4,000-\mathrm{Hz}$ frequency range, in or both ears; or, with alteration in the acoustic immittance with type B or C curve). The full description of the sample and the evaluation to which they were submitted, including the description of the instruments and procedures, are available in Garcia, MomensohnSantos and Vilhena ${ }^{23}$.

\section{Instruments}

The Duration Pattern Test (DPT) ${ }^{26}$ was used to identify auditory temporal orderingskill. It consists of flute musical sound stimuli (melodic tones) of long $(2,000 \mathrm{~ms})$ and short $(500 \mathrm{~ms})$ duration. They are applied in ten sequences of three stimuli, and ten sequences of four stimuli, with fixed frequency of 440 $\mathrm{Hz}$ and interstimulus interval of 6 milliseconds. The tests were carried out binaurally in a sound booth, with supraaural headphones at $50 \mathrm{~dB}$ ns. The clinical two-channel audiometer, brand Maico MA 42, was used, along with TDH-39P headphones, brand Telephonics, attached to a computer, by means of an interface cable, from the headphone plug to one of the $\mathrm{CD} /$ tape plugs of the audiometer.

The Reading Perceptual Scale (IRPS) ${ }^{27}$ is a set of evaluations used as a visual processing disorder risk indicator. It's composed of: i) a questionnaire with 32 items on difficulty and discomfort while reading (Table 1); ii) tasks that intensify visual stress (e.g., Figure 1a); and, iii) a selection of colored overlays (Figure 1b). The IRPS questionnaire on reading difficulty and discomfort has positive and moderate correlation $(r=0.69, p<$ $0.001)^{23}$. The colored overlays are acetate sheets in ten tones, used over the text since the 1980s to improve reading performance and to increase visual comfort of children and adults with symptoms of visual stress in reading $23,25,28$.

Table 1. Reading Perceptual Scale Difficulty and Discomfort Questionnaire

\begin{tabular}{ll|}
\hline Difficulty Questionnaire & Discomfort Questionnaire \\
\hline 1. Do you accidentally skip lines or phrases? & 1. Do your eyes bother you? \\
2. Do you lose track when reading? & 2. Do your eyes get red or teary? \\
3. Do you mistake words? & 3. Do they hurt or burn? \\
4. Do you skip words unintentionally? & 4. Do they get dry, itchy or gritty? \\
5. Do you read the same line over several times? & 5. Do you rub your eyes, or around them? \\
6. Do you confuse words from the top or bottom line? & 6. Do you get tired or sleepy? \\
7. Do you avoid reading in silence and aloud? & 7. Does your head bother you? \\
8. Is your reading slow or interrupted? & 8. Do you have headaches? \\
9. Are you bothered by white or bright pages? & 9. Do you feel dizzy? \\
10. Do you look away to the distance, rest or make pauses? & 10. Do you feel stomach sick, or have stomachaches? \\
11. Do you get anxious, restless or easily distracted? & 11. Do you open your eyes wide? \\
12. Do you feel that reading gets progressively harder? & 12. Do you squint or frown? \\
13. Do you use a bookmark or your finger? & 13. Do you blink too often? \\
14. Is it hard for you to understand what you read? & 14. Do you approach or move away from the page? \\
15. Is it hard for you to remember what you've read? & 15. Do fluorescent lights bother you when you read? \\
16. Do you have to make an effort to keep on reading? & 16. Is it more difficult to read under white light? \\
\hline
\end{tabular}


(a)

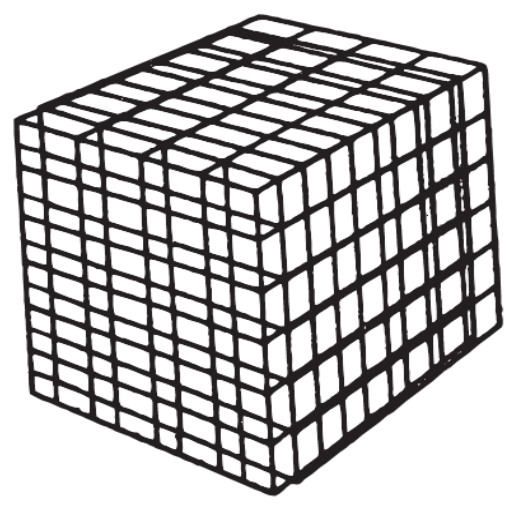

(b)

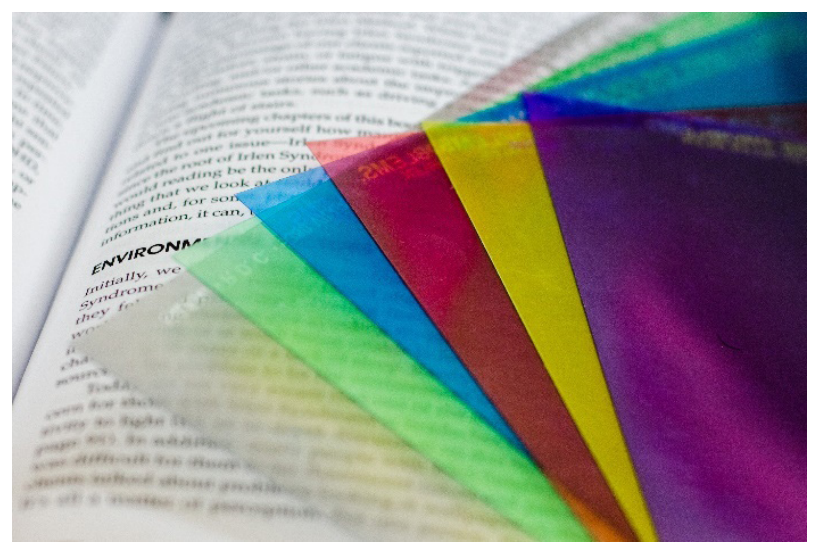

Figure 1. (a) Example of visual stressor from the Reading Perceptual Scale; (b) Example of colored overlays

The Rate of Reading Test (RRT) ${ }^{29}$ was used to measure the effect of the colored overlays on the reading rate, and to screen the participants with visual processing disorder. It is composed of five different lists, one for training and four for testing (e.g., Figure 2). The lists are composed of 15 high frequency words ${ }^{30}$ repeated in 20 lines, adding up to 300 words. It's printed in reduced font (size 9) and single line spacing, thus diminishing the scope of saccadic eye movement and increasing visual effort. Each list is read aloud for up to one minute.

lua fada mar vida time pé ar rei dia já rua pão bala ovo uva mar rei pé ar rua fada uva ovo pão bala lua vida dia time já ovo bala dia mar pão lua já vida fada ar time rua rei uva pé rua pão uva ovo vida ar pé rei bala dia lua já fada mar time vida fada lua dia rei time rua já mar pé uva ar bala pão ovo uva dia rei time bala já ar pão pé fada vida ovo lua mar rua já vida lua ovo ar pé dia time bala uva mar rua rei fada pão rei uva bala já fada vida mar pão rua lua ovo dia time pé ar pé fada time mar dia rua lua rei ovo bala já pão ar vida uva ar ovo rua bala rei já time dia vida pão uva fada pé lua mar lua fada mar time vida pé ar rei dia já rua pão bala ovo uva mar rei pé ar rua fada uva ovo pão bala lua vida dia time já ovo bala dia mar pão lua já vida fada ar time rua rei uva pé rua pão uva ovo vida ar pé rei bala dia lua já fada mar time vida fada lua dia rei time rua já mar pé uva ar bala pão ovo uva dia rei time bala já ar pão pé fada vida ovo lua mar rua já vida lua ovo ar pé dia time bala uva mar rua rei fada pão rei uva bala já fada vida mar pão rua lua ovo dia time pé ar pé fada time mar dia rua lua rei ovo bala já pão ar vida uva ar ovo rua bala rei já time dia vida pão uva fada pé lua mar

Figure 2. Example of one of the lists from the Rate of Reading Test 


\section{Procedures}

The data collection took place at the school itself and at the Integrated Medical Service of the Public Health Care System. The evaluations were carried out individually, at a time not interfering with school content learning, in a separate room, apart from the ongoing traffic of people and other noises. All the participants were examined by an ophthalmologist, with the purpose of checking visual acuity limitation, indicated by refractive error, which could cause reading difficulty due to loss of sharpness. Those who presented ophthalmic alteration were excluded from the study and referred for appropriate guidance and therapeutic intervention. Initially, a rapport was established in order to achieve a good interaction with the participant.

The evaluation of auditory temporal ordering skill, by means of the DPT, was carried out always by the same speech-language-hearing therapist, so as to avoid deviations and differences in the collection procedures. The participant was asked to verbally name the sequence of tones they heard. The number and the percentage of right answers were registered; an answer was considered wrong when the sequence of sounds presented was inverted. For children nine years old and over, the normality standard for the three-sound DPT is $100 \%$ of right answers; as for the four-sound, it's $90 \%$ of right answers.

The participants answered the IRPS questionnaire (Table 1), which includes questions on reading lines, omitting words or lines, losing track, poor handwriting, inefficiency in copying from books or from the board, rubbing the eyes, blinking excessively, tearing, shading the eyes, aversion to strong lights, among others. The score of the items was given according to the frequency with which it occurred during reading activities: frequently (1 point), sometimes (0.5 point), never, or couldn't answer (0 point). Then, they were submitted to visual effort tasks, in which discomfort is progressive until visual stress is manifested; its mitigation was induced through the use of one or even two colored overlays, presented in a patterned and sequential manner.

In the application of the RRT, the child read each word aloud, sequentially, from left to right, as fast as possible, in each of the five lists. The training list is applied for the participant to get used to reading decontextualized words in sequence. The first list of the test was overlaid with the self-chosen colored overlay, followed by the second and third lists, read without an overlay, and the fourth list, read with the overlay again (ABBA design for controlling practice effect).
The results are given in numbers of words correct per minute (WCPM) and in the percentage of reading rate improvement when using the colored overlay. Improvement of at least $\geq 5 \%$ in reading rate with the use of colored overlays was considered as a criterion to screen the children with visual processing alterations. The index of $\geq 5 \%$ is predictive of the sustained/ prolonged use of colored overlays (predictive validity, sensibility of 60 to $73 \%)^{31-33}$.

\section{Data analysis}

The IBM SPSS Statistics (version 21.0, Chicago, Illinois, USA) was used for all data analysis. For evaluating the association between variables, the chi-squared test of independence and odds-ratio calculation was applied. In order to establish the clinical significance of the differences, Cohen's $d$ of 0.2 represents small effect size; 0.5 , medium effect; and 0.8 , large effect. $P$-value inferior to 0.05 was considered statistically significant.

\section{RESULTS}

In the Duration Pattern Test, 42 (61.8\%) participants presented normal results, whereas the other 26 (38.2\%) were screened with auditory temporal ordering skill (Table 2). The sample classification of the DPT was used in the analysis of the IRPS and RRT to identify the association between the auditory processing and the visual processing. Participants with alterations in the DPT, when analyzed taking the IRPS reading difficulty and discomfort questionnaire as a reference, reported more visual symptoms $(11.9 \pm 7.5)$ than the group with normal DPT (8.6 \pm 5.8) $\left(\mathrm{F}_{(1.66)}=4.3 ; p=0.043\right.$; $d=0.49$ ).

Participants with altered DPT, when evaluated by the RRT, presented lower reading rate (RRT $=85.6 \pm$ 20.0 words correctly read per minute), when compared to the group with normal DPT (RRT $=100.0 \pm 20.6$ WCPM) $\left(F_{(1.66)}=8.1 ; p=0.006 ; d=0.71\right)$. In the RRT evaluation, 27 (39.7\%) of the students presented improvement of reading rate with the use of colored overlay (improvement of at least $\geq 5 \%$ ), whereas 41 (60\%) didn't present improvement (performance $<5 \%$ ). Among the children with alteration in the DPT, 58\% improved the reading rate with the use of the colored overlay, while $29 \%$ of the control group presented improvement (Table 2). That is, students who presented alteration in the DPT were three times more likely to improve their reading rate with the colored overlay, when compared to their peers with normal DPT (Odds Ratio $=3.41 ; \mathrm{Cl}=1.22-9.5$; chi-square $=5.69$; $p=0.017)$. 
Table 2. Frequency and percentage of students in the classifications of screening for auditory processing (Duration Pattern Test, DPT) and for visual processing (Rate of Reading Test, RRT)

\begin{tabular}{|c|c|c|c|c|c|c|}
\hline & & & \multicolumn{2}{|c|}{ Visual (RRT) } & \multirow{2}{*}{ Total } & \multirow{2}{*}{$p$ value } \\
\hline & & & Altered & Normal & & \\
\hline \multirow{4}{*}{$\begin{array}{c}\text { Auditory } \\
\text { (DPT) }\end{array}$} & & Frequency & 15 & 11 & 26 & \multirow{5}{*}{0.017} \\
\hline & Altered & $\%$ in the altered DPT & $57.7 \%$ & $42.3 \%$ & $100.0 \%$ & \\
\hline & Normal & Frequency & 12 & 30 & 42 & \\
\hline & & $\%$ in the normal DPT & $28.6 \%$ & $71.4 \%$ & $100.0 \%$ & \\
\hline \multicolumn{2}{|c|}{ Total } & $\begin{array}{l}\text { Frequency } \\
\% \text { in total sample }\end{array}$ & $\begin{array}{c}27 \\
39.7 \%\end{array}$ & $\begin{array}{c}41 \\
60.3 \%\end{array}$ & $\begin{array}{c}68 \\
100.0 \%\end{array}$ & \\
\hline
\end{tabular}

Key: DPT: Duration Pattern Test; RRT: Rate of Reading Test; Auditory Processing (Altered = accuracy lower than $<100 \%$ in the three sounds, and $<90 \%$ in the four sounds); Visual Processing (Altered $=$ improvement of at least $\geq 5 \%$ in reading rate with the use of colored overlay; Normal $=$ difference $<5 \%$ in reading rate). Source: elaborated by the authors.

\section{DISCUSSION}

The results obtained from this study, based on screening instruments, demonstrate that there is a association between auditory processing and visual processing. About $38 \%$ of the students presented alteration in screening for auditory temporal ordering skill, which is the ability to distinguish correctly the order in which an acoustic signal occurs in a specific time period. It was verified that these children with auditory alteration had more visual stress symptoms, lower reading rate, and greater chances of improving reading speed with the use of colored overlays, when compared to the control group. That is, children screened with alteration in the auditory temporal processing probably have a deficit in visual processing as well.

These results are coherent with the deficit in the visual magnocellular system in dyslexics. Pammer and Wheatley ${ }^{14}$ verified that a group of 21 dyslexics had a poorer performance in detecting a visual stimulus selective of the magnocellular system, when compared to 19 readers of the control group $\left(F_{(1.38)}=13.6\right.$, $p<0.001$ ), with diminished sensibility in comparison with the standardized age cohort. In the study by Flint and Pammer ${ }^{12}$, illiterate adults obtained the same performance as that of normal and semi-illiterate readers in temporal and spatial tasks specific of the visual magnocellular system, and these three groups had a better performance than the group of dyslexic readers. The authors conclude ${ }^{12}$ that this functional failure of the dorsal visual pathway in dyslexia is probably not a consequence of the lack of reading; they point to a causal role of the magnocellular processing, instead.

The evaluation of the abilities that sustain learning to read, as well as of the disorders that may affect its proficiency becomes more and more important by the day. It was verified that the DPT, the IRPS and the RRT are important resources in the clinic to screen children suspect of presenting alteration in the auditory and visual processing. The RRT makes it possible to measure the number of words correctly read per minute (reading rate), and it's sensitive to identify the effect of colored overlays, in a quick and simple way, at low cost. The RRT has a low degree of linguistic processing, as it requires high frequency nouns, with neither syntactic nor semantic relation between them, to be recognized and read aloud. The non-requirement of understanding for the word, sentence and text (textual micro- or macrostructure) reduces the access to the semantic system and high-order cognitive components. These factors, if not controlled, may increase variability in reading rate score. Furthermore, the reduced structural spacing configuration between the lines in the RRT is similar to medium spatial frequency sinusoidal line patterns ( 2 to 5 cycles per degree), which are recognized as inducing triggers of visual perceptual distortions and discomfort ${ }^{34}$.

Evans, Allen and Wilkins ${ }^{15}$ consulted 22 experienced practitioners about visual stress diagnosis indicators. They consider that there should be present at least threeof six typical symptoms: i) words move when reading; ii) words merge together; iii) patterns or shadows in the text (e.g., rivers); iv) text seems to stand out in 3-D above the page; v) words or letters fade or darken; and, vi) discomfort with certain artificial lights and flicker. Moreover, there must be present at least two of three investigation signs: i) voluntary and spontaneous use of colored overlays for three months or more; ii) improvement in reading rate $\geq 15 \%$ with the use of overlays; and, iii) visual difficulty and discomfort with medium spatial frequency sinusoidal grating. 
Garcia et al. ${ }^{23}$ verified, in the same sample ofparticipants of this study ( $N=68)$, that $31 \%, 22 \%, 18 \%$ and $13 \%$ of students presented an improvement of at least $\geq 5 \%, \geq 8 \%, \geq 10 \%$ and $\geq 15 \%$ in reading rate with the use of colored overlays, respectively. The strictest improvement cutoff criterion of $\geq 15 \%$ in the reading rate with overlays has clinical significance, as it's a visual stress diagnostic sign ${ }^{15}$, and it represents an increase in reading rate beyond the intraindividual variation interval ${ }^{35}$. That is, at least one in every ten children presents a significant improvement in reading rate with colored overlays. These results with a Brazilian sample confirm the values found in different international studies ${ }^{32-33,36}$, providing criteria validity evidence for the Rate of Reading Test.

Veszeli and Shepherd ${ }^{25}$ evaluated the effect of colored overlays in 106 typical children, aged four to seven years, enrolled in the $1^{\text {st }}$ and $3^{\text {rd }}$ grades. The authors verified significant improvement in the reading rate both with the overlay chosen as the most effective $\left(F_{(1.104)}=332, p<0.001\right)$ and with the overlay that offered greatest visual comfort $\left(F_{(1.104)}=116, p<0.001\right)$, when compared to the baseline. The greatest reductions in reading time occur among younger readers, which indicates that colored overlays may be particularly efficient for the least proficient readers. Veszeli and Shepherd reported that all participants, except four children, reduced reading time with one of the overlays; moreover, all of them, except one, reported better visual sharpness of the text. The use of colored overlays also improved visual acuity for reading (close view, at 40 centimeters) in more than $40 \%$ of the children, whose average of the Snellen equivalent passed from 20/25 to $20 / 20(p<0.001)$.

Hollingsworth et al. ${ }^{37}$ reinforced that deaf children are doubly disadvantaged in reading, once they present diminished visual and phonological abilities. The findings have shown that deaf participants had greater ametropia, with reduced amplitude of accommodation, remote near point of convergence, and lower rate of reading. The authors ${ }^{37}$ verified that $100 \%(n=$ $31 / 31$ ) of the deaf participants had chosen at least one colored overlay, yellow being the most frequent one $(45 \%, 14 / 31)$. As for the hearing control group, $67 \%$ ( $n$ $=26 / 39$ ) had chosen at least one overlay, none of the participants opting for the yellow. In the deaf who had chosen yellow, the reading rate increased in $18 \%$, with no statistical difference among the other deaf participants, nor in the hearing control group.
Reading presupposes different visual abilities, such as binocular synchronicity and focus, comfort, sharp and stable images, efficient eye movement, accurate dynamic processing, and quick interpretation after a short period of eye fixation. A study ${ }^{38}$ has demonstrated that fifth grade students with reading and writing difficulties (RWD, $n=11$ ) presented significant difference in dynamic visual acuity (though not in static acuity) and in saccadic movement, when compared to the control group $(n=7)(p<0.05)$. The ocular motor function was evaluated through three electrodes placed on the face, whose results were registered by the polygraph needle on graph paper. In the saccadic movement analysis, all the participants in the RWD group registered irregularities in eyeball movement as they followed with their look the researcher's finger, which was sporadically lifted in random spots of the horizontal plane. The unanimous difficulty of the RWD group in following a target in space may have been a determining factor for poor school performance, hindering reading and writing development, since such abilities require refined eye movement control in search of letter sequencing on paper.

In this study, students with alteration in screening for auditory processing reported more visual stress symptoms in the IRPS questionnaire than those with normal DPT. Equivalent result was found in a research ${ }^{18}$ that identified that a group of dyslexic college students $(n=16)$ reported more visual stress symptoms than the control group without dyslexia $(n=26)\left(F_{(1.40)}=\right.$ $15.1, p<0.05)$. Regardless of conditions, one of the ways of reducing visual stress symptoms, particularly in prolonged reading activities, has been through colored overlays. Garcia, Momensohn-Santos, Vilhena ${ }^{23}$ verified that students identified with severe visual discomfort while reading $(n=11)$ were three times more likely (odds ratio $=3.36$ ) to improve the reading rate with the overlay they had chosen, when compared to the participants with less discomfort.

Auditory and visual sensorial integration is highlighted as of great importance to improve school performance of children. Temporal organization, which is the serialization of the order of facts in time, is an important ability to learn how to read. The identification and intervention processes employed in patients with dyslexia are different from those used in visual processing disorders ${ }^{17}$. The diagnosis and treatment of dyslexia involve phonological and lexical intervention sessions $^{3,39}$. It's essential to enable education professionals to identify early the symptoms and signs of 
visual stress in the reading of literate students, particularly those with alteration in auditory processing, so that they may be referred for health professionals to investigate and intervene in ophthalmic problems and visual processing disorders ${ }^{15,40}$.

\section{CONCLUSION}

Students with alteration in auditory temporal processing are more likely to present concomitant impairment in visual processing, when compared to their peers with normal auditory processing. Health and education professionals must examine all schoolage children in order to identify, early, the alterations in auditory and visual processing and, thus, intervene. All instruments employed in this study, i.e., DPT, IRPS and RRT, have shown to be important tools to investigate the skills they measure, namely: auditory processing, visual processing, and reading rate, respectively. In the context of the conditions investigated in this study, the genetic level (incidence in the family), brain level (magnocellular deficit), cognitive level (auditory and visual temporal processing deficit), and behavior level (reading, spelling and writing difficulty), should be taken into account.

\section{REFERENCES}

1. Carvalho NG, Novelli CVL, Colella-Santos MF. Factors in childhood and adolescence that may influence the auditory processing: a systematic review. Rev. CEFAC. 2015;17(5):1590-603. Doi: 10.1590/1982-0216201517519014.

2. Dehaene S. Os neurônios da leitura: como a ciência explica a nossa capacidade de ler. Porto Alegre: Penso; 2012.

3. Pedrosa BAC, Dourado JS, Lemos SMA. Lexical development, speech language disorders and school performance: literature review. Rev. CEFAC. 2015;17(5):1633-42. Doi: 10.1590/1982-0216201517519913

4. Boets B, Wouters J, Van Weiringen A, De Smedt B, Hesquière $P$. Modelling relations between sensory processing, speech processing, orthographic and phonological ability, and literacy achievement. Brain Lang. 2008;106(1):29-40.

5. Matos GGO, Frota S. Temporal resolution in sensorineural hearing loss. Audiol. Commun. Res. 2013;18(1):30-6. Doi: 10.1590/ S2317-64312013000100007.
6. Oliveira AC, César CPHAR, Matos GG, Passos PS, Pereira LD, Alves $T$ et al. Hearing, language, motor and social skills in the child development: a screening proposal. Rev. CEFAC. 2018;20(2):218-27. Doi: 10.1590/1982-0216201820216617.

7. Stein J, Walsh V. To see but not to read; the magnocellular theory of dyslexia. Trends Neurosci. 1997;20(4):147-52.

8. Vidyasagar TR, Pammer K. Dyslexia: a déficit in visuo-spatial attention, not in phonological processing. Trends Cogn Sci. 2010;14(2):57-63.

9. Arseno VA, Carvalho CA, Castro MP, Duarte SG, Reis $A C M B$, Marangoni $A C$ et al. Comparative study of temporal resolution test results in young adults. Rev. CEFAC. 2016;18(6):1277-84. Doi: 10.1590/1982-021620161864312

10. Vidyasagar TR. Reading into neuronal oscillations in the visual system: implications for developmental dyslexia. Front Hum Neurosci. 2013;7(1):811. Doi: 10.3389\%2Ffnhum.2013.00811

11. Stein J. The current status of the magnocellular theory of developmental dyslexia. Neuropsychologia. 2019;130:66-77. Doi: 10.1016/j. neuropsychologia.2018.03.022.

12. Flint $\mathrm{S}$, Pammer $\mathrm{K}$. It is the egg, not the chicken; dorsal visual deficits present in dyslexia are not present in illiterate adults. Dyslexia. 2018;25(1):69-83. Doi: 10.1002/dys.1607

13. Gori S, Seitz AR, Ronconi L, Franceschin S, Facoetti A. Multiple causal links between magnocellulardorsal pathway deficit and developmental dyslexia. Cereb Cortex. 2016;26(11):4356-69. Doi: 10.1093/ cercor/bhv206

14. Pammer K, Wheatley $C$. Isolating the $M(y)$-cell response in dyslexia using the spatial frequency doubling illusion. Vision Res. 2001;41(16):2139-47. Doi: 10.1016/S0042-6989(01)00092-X

15. Evans BJW, Allen PM, Wilkins AJ. A Delphi study to develop practical diagnostic guidelines for visual stress (pattern-related visual stress). J Optom. 2017;10(3):161-8. Doi: 10.1016/j. optom.2016.08.002

16. Soares A, Gontijo LS. Production of knowledge: genetic basis, biochemical and immunological of Meares-Irlen Syndrome. RevBras Oftalmol. 2016;75(5):412-5. Doi: 10.5935/0034-7280.20160084

17. Guimarães MFCR, Vilhena DA, Guimarães RQ. Relação do processamento óptico, neurovisual e 
cognitivo nas dificuldades de leitura. Acta científica. 2017;8(1):193-212.

18. Henderson LM, Tsogka N, Snowling MJ. Questioning the benefits that coloured overlays can have for reading in students with and without dyslexia. J Res Spec Educ Needs. 2013;13(1):57-65. Doi: 10.1111/j.1471-3802.2012.01237.x

19. Loew SJ, Watson K. The prevalence of symptoms of scotopic sensitivity/Meares-Irlen syndrome in subjects diagnosed with ADHD: does misdiagnosis play a significant role? Hrvatska revija za rehabilitacijskaistraživanja. 2013;49(Supplement):64-72.

20. Ludlow AK, Wilkins AJ. Atypical sensory behaviours in children with Tourette's Syndrome and in children with Autism Spectrum Disorders. Research in Developmental Disabilities. 2016;56(1):108-16. Doi: 10.1016/j.ridd.2016.05.019.

21. Beasley IG, Davies LN. Visual stress symptoms secondary to stroke alleviated with spectral filters and precision tinted ophthalmic lenses: a case report. Clin Exp Optom. 2013;96(1):117-20. Doi: 10.1111/j.1444-0938.2012.00794.x

22. Evans BJW, Allen PM. A systematic review of controlled trials on visual stress using Intuitive Overlays or the Intuitive Colorimeter. J Optom. 2016;9(4):205-18. Doi: 10.1016/j. optom.2016.04.002

23. Garcia ACO, Momensohn-Santos TM, Vilhena DA. Effects of spectral overlays on reading performance of brazilian elementary school children. Folia Phoniatr. Logop. 2017;69(5-6):219-25. Doi: 10.1159/000484139

24. Tosta S, Irlen H, Lewine J, Annibali J. Precisiontinted coloured filters: a successful intervention for medically resistant headaches and migraines after brain injury. In Brain Inj. 2014;28(5-6):683.

25. Veszeli J, Shepherd AJ. A comparison of the effects of the colour and size of coloured overlays on young children's reading. Vision Res. 2019;156(1):73-83. Doi: 10.1016/j.visres.2019.01.006.

26. Pereira LD, Schochat E. Testes auditivos comportamentais para avaliação do processamento auditivo central. São Paulo: Pró-Fono. 2011.

27. Irlen H. Irlen Reading Perceptual Scale (IRPS). Long Beach, CA: Perceptual Development Corporation; 2003.

28. Vilhena DA, Guimaraes MFCR, Pinheiro AMV, Guimaraes RQ. Tratamento do estresse visual na leitura: características físicas e mecanismos neurais de ação das lâminas espectrais (overlays). Paidéia. 2018;13(19):3131-9.

29. Vilhena DA, Guimarães MFCR, Guimarães $R Q$, Pinheiro AMV. Adaptação do Teste de Taxa de Leitura: seleção dos vocábulos. Trabalho premiado na categoria Pesquisador Sênior. Encontro Mineiro de Neuropsicologia Escolar, Universidade Federal de Minas Gerais, Belo Horizonte. 2019.

30. Pinheiro ÂMV. Frequency of occurrence of words in textbooks exposed to brazilian children in the early years of elementary school. Childes - Child Language Data Exchange System. 2015. Disponível em: http://childes.talkbank.org/derived

31. Northway N. Predicting the continued use of overlays in school children--a comparison of the Developmental Eye Movement test and the Rate of Reading Test. Ophthalmic Physiol Opt. 2003;23(5):457-64.

32. Wilkins AJ, Jeanes RJ, Pumfrey PD, Laskier M. Rate of Reading Test: its reliability, and its validity in the assessment of the effects of coloured overlays. Ophthalmic Physiol Opt. 1996;16(6):491-7. Doi: 10.1046/j.1475-1313.1996.96000282.x

33. Wilkins AJ, Lewis E, Smith F, Rowland E, Tweedie W. Coloured overlays and their benefit for reading. J Res Read. 2001;24(1):41-64. Doi: 10.1111/1467-9817.00132

34. Allen PM, Hussain A, Usherwood C, Wilkins AJ. Pattern-related visual stress, chromaticity, and accommodation. Invest Ophthalmol Vis Sci. 2010;51(12):6843-9. Doi: 10.1167/iovs.09-5086

35. Srinivasan K, Krishnan G, Wilkins A, Allen P. Reliability and validity of a Kannada rate of reading test. Indian J Ophthalmol. 2018;66(5):630-3. Doi:10.4103/ijo.IJO_807_17

36. Kriss I, Evans BJ. The relationship between dyslexia and Meares-Irlen syndrome. $J$ Res Read. 2005;28(3):350-64. Doi: 10.1111/j.1467-9817.2005.00274.x

37. Hollingsworth RS, Ludlow AK, Wilkins AJ, Calver RI, Allen PM. Visual performance and the use of colored filters in children who are deaf. Optom Vis Sci. 2015;92(6):690-9. Doi: 10.1097/ OPX.0000000000000595

38. Sales R, Colafêmina JF. The influence of eye movement and the vestibular-ocular reflex in reading and writing. Rev. CEFAC. 2014;16(6):1791-7. Doi: 10.1590/1982-0216201419013

39. Silva C, Capellini SA. Efficacy of phonological intervention program in students at risk for 
dyslexia. Rev. CEFAC. 2015;17(6):1827-37. Doi: 10.1590/1982-021620151760215

40. Monger L, Wilkins A, Allen P. Identifying visual stress during a routine eye examination. JOptom. 2015;8(2):140-5. Doi: 10.1016/j.optom.2014.10.001 